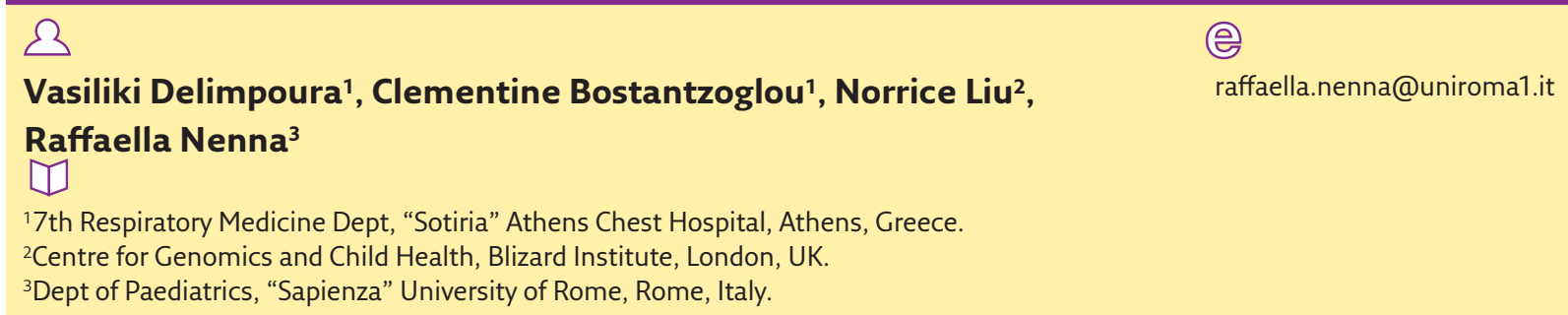

\title{
Novel therapies for severe asthma in children and adults
}

\section{Landmark papers in respiratory medicine}

Asthma is a heterogeneous disease usually characterised by chronic airway inflammation. It is defined by a history of symptoms such as wheeze, shortness of breath, chest tightness and cough, along with variable airflow limitation [1]. Recently, "cluster" analyses have provided insight into specific subtypes among asthma patients, which share phenotypic characteristics.

Asthma is a global health burden. It is estimated that more than 300 million people are affected and the number is increasing, particularly among children [2].

Severe asthma is a discrete clinical entity with an increased risk of exacerbations, poor quality of life and poor asthma control. A European Respiratory Society/American Thoracic Society task force defined severe asthma for patients aged $\geq 6$ years as asthma that requires treatment with guidelinesuggested medications for Global Initiative for Asthma (GINA) steps 4-5 (high-dose inhaled corticosteroids (ICS) and long-acting $\beta_{2}$-agonists (LABA) or leukotriene modifier/theophylline) for the previous year or systemic corticosteroids for $\geq 50 \%$ of the previous year [3]. Severe asthma affects about $4.5 \%$ of the paediatric asthma population [4].
Novel therapies have been identified for severe asthma and phenotype-guided treatments are available [5]. For those who remain poorly controlled, add-on treatments with monoclonal antibodies are considered [3]

\section{Anti-IgE antibody}

IgE has a central role in the pathophysiology of allergic inflammation and asthma. Omalizumab is a recombinant DNA-derived humanised $\lg _{1}$ monoclonal antibody against IgE [6]. It binds to circulating (free) lgE; thus, it inhibits lgE binding to high-affinity (FcERI) or low-affinity receptors on basophils, mast cells and dendritic cells. As a result, it inhibits IgE-mediated response and downregulates high-affinity receptors on mast cells and basophils [7].

Omalizumab is approved as an add-on treatment for patients $>6$ years old with severe persistent allergic asthma and elevated serum IgE whose asthma remains uncontrolled with corticosteroids (ICS and/or oral corticosteroids (OCS)) and LABA or requires high-dose treatment to maintain good
Cite as: Delimpoura V, Bostantzoglou C, Liu N, et al. Novel therapies for severe asthma in children and adults Breathe 2018; 14: 59-62. 
asthma control [1]. The criteria for omalizumab use are confirmed lgE-dependent severe persistent allergic asthma and serum total IgE levels that range $30-700 \mathrm{IU} \cdot \mathrm{mL}^{-1}$ in USA or $>30-<1500 \mathrm{IU} \cdot \mathrm{mL}^{-1}$ in Europe. Omalizumab appears to have a good safety profile, with the most common adverse effects being anaphylaxis and injection site reactions, usually of mild-to-moderate severity and short in duration [8].

\section{Anti-interleukin-5 antibodies}

Asthma is often characterised by eosinophilic inflammation. Eosinophils have a crucial role in the pathogenesis of asthma, being implicated both in airway inflammation and in airway remodelling. Interleukin (IL)-5 is the major cytokine required for eosinophil proliferation, differentiation, maturation, migration, survival and prevention of apoptosis [9]. Anti-IL-5 antibodies inhibit the activity of IL-5 [10]. Two monoclonal antibodies for IL-5 have been approved as a treatment option (GINA step 5, add-on treatments) for patients aged $\geq 12$ years with severe eosinophilic asthma whose asthma is uncontrolled on treatment with corticosteroids (ICS and/or OCS) and LABA, or who require high-dose corticosteroid treatment to maintain good asthma control [1] Blood eosinophilia and previous exacerbations are the major criteria for the use of anti-IL-5 therapy.

\section{Paediatric patients}

DeschildRe et al. [11] performed a 1-year observational study on 104 children (aged 6-18 years) with severe atopic asthma who were commenced on omalizumab under tertiary care. The majority of the studied population had polysensitisation, allergic rhinitis and IgE levels above the treatment threshold of $700 \mathrm{IU} \cdot \mathrm{mL}^{-1}$. With omalizumab use, there was significant improvement of asthma control (assessed according to GINA) in $86 \%$ of the studied patients. Exacerbation frequency was reduced by $72 \%$ compared to the previous year, resulting in less healthcare utilisation. Forced expiratory volume in $1 \mathrm{~s}$ (FEV1) and forced expiratory flow at $25-75 \%$ of forced vital capacity improved $(+4.9 \%$ and $+9.5 \%$ respectively) whilst on omalizumab. Corticosteroid use was also decreased, with a $30 \%$ reduction in ICS use, and all children previously on systemic corticosteroids were able to discontinue its use. These data showed even bigger impact than previous efficacy trials. Mean baseline lgE levels were not different between different symptom control groups, and no relationship between IgE level and the above outcomes was identified. Age, however, was found to be associated with treatment response. Symptoms in younger children (aged $<12$ years) were less controlled, resulting in more exacerbations compared to the older age group.
Severe asthma is a heterogeneous disease; a portion of the patient population does not fit the atopic criteria for anti-IgE monoclonal antibody treatments. There is evidence that $\lg \mathrm{E}$ is a risk factor for asthma regardless of allergy status [12] and that baseline lgE is not associated with asthma symptom control [11].

PILLAl et al. [13] randomised 18 symptomatic nonatopic asthmatic patients to receive either omalizumab or placebo, while reducing conventional existing therapy: replacing inhaled and oral antileukotriene or theophylline with regular budesonide/formoterol combination therapy with as required terbutaline, and reducing regular OCS. They found that omalizumab significantly reduced bronchial mucosal lgE (-5.44 in omalizumab versus $+4.98 \mathrm{IU} \cdot \mathrm{mL}^{-1}$ in placebo), and improved lung function (FEV1 predicted $+11 \%$ improvement in omalizumab versus $-2 \%$ in placebo)

A post hoc analysis performed by MAGNAN et al. [14] evaluated the effect of mepolizumab (a humanised $\operatorname{lgG}_{1}$, anti-IL-5, monoclonal antibody that binds to IL-5 and prevents binding to its receptor) in patients previously treated with omalizumab, which was discontinued mostly due to poor efficacy. Regardless of whether patients were previously treated with omalizumab, mepolizumab was shown to reduce exacerbations and steroid use, improved asthma control and quality of life. Mepolizumab seemed to be beneficial to patients with severe atopic asthma, who responded inadequately to omalizumab, and should therefore be considered as a treatment option.

\section{Adult patients}

There are plenty of studies suggesting the efficacy of omalizumab on numerous clinical parameters in allergic asthma, including exacerbation rate, hospitalisations, need for OCS or reliever medication and corticosteroid treatment, and asthma control. Studies have demonstrated that it reduces exacerbation rate, and the number of hospitalisations and emergency visits [8, 15-17]. In patients receiving omalizumab, there was a reduction in asthma exacerbations with an odds ratio of 0.55 , which represents an absolute reduction from $26 \%$ for patients suffering an exacerbation on placebo to $16 \%$ on omalizumab over 16-18 weeks, and a reduction in number of hospitalisations with an odds ratio of 0.16 that represents a reduction in risk from $3 \%$ with placebo to $0.5 \%$ with omalizumab over $28-60$ weeks [8]. The INNOVATE study showed that omalizumab reduced the asthma exacerbation rate by $26 \%$ and the rate of severe exacerbations by $50 \%$ [17]. It also improves lung function, quality of life and asthma control symptoms $[8,17,18]$.

Anti-lgE treatment is not only effective in improving clinical parameters but has also shown effectiveness in interrupting inflammation and 
preventing or even reversing airway remodelling in patients with uncontrolled allergic severe asthma [19]. DJUKANOvic et al. [20] showed that treatment with omalizumab for 16 weeks resulted in reduction of sputum and airway eosinophilia, and of inflammatory markers. Other studies suggest that it inhibits the expression and production of pro-inflammatory cytokines such as transforming growth factor- $\beta$ and endothelin- 1 , which are associated with airway remodelling changes [21]. KANG et al. [22] proved that omalizumab decreased airway hyperresponsiveness, bronchoalveolar lavage fluid inflammatory cell counts, IL-5 and IL-13 levels, peribronchial collagen deposition, hydroxyproline, and $\alpha$-smooth muscle actin in murine models. Rотн et al. [23] have demonstrated that omalizumab has a role in preventing human airway smooth muscle cell proliferation and extracellular matrix and collagen deposition in allergic asthmatics. Moreover, Rıccio et al. [24] showed significant reduction in reticular basement membrane thickness in bronchial biopsies from patients with severe allergic asthma after 1 year of treatment with omalizumab.

The optimal treatment duration has not been determined but, in general, it is considered an effective treatment approach to continue treatment in responders. Half of patients with good clinical response will relapse at a median of 13 months after discontinuation [25]. Nonresponders must be recognised as soon as possible and therapy should be discontinued. It is proposed that if there is no clinical response within 4 months of initiating treatment, further administration of omalizumab will be not beneficial [3]. Th2 biomarkers (blood eosinophil levels $\geq 280$ per $\mu \mathrm{L}$, exhaled nitric oxide fraction $\geq 24 \mathrm{ppb}$ or periostin level $\geq 53 \mathrm{ng} \cdot \mathrm{mL}^{-1}$ have been proposed as predictors for a good omalizumab response [26].

Mepolizumab in clinical trials reduced exacerbations by $50 \%$, improved lung function and was associated with improvements in markers of asthma control in patients with severe eosinophilia and two or more exacerbations in the previous year [27-29]. Moreover, mepolizumab had a significant corticosteroid-sparing effect in patients requiring daily OCS therapy to maintain asthma control, resulting in a $50 \%$ reduction of the dose of oral steroids in the group of patients with blood eosinophilia compared to placebo group [27]. Mepolizumab appears to have a good safety profile. Adverse effects include injection site and anaphylactic reactions in rare cases.

Reslizumab is the second humanised, anti-IL-5, monoclonal antibody that disrupts eosinophilic maturation and promotes programmed cell death. In clinical trials, reslizumab reduced asthma exacerbations and blood eosinophil counts and improved FEV 1 and Asthma Control Questionnaire score [30, 31]. CASTRo et al. [30] reported results from two multicentre, parallel, double-blind, randomised, placebo-controlled, phase 3 trials in patients with uncontrolled asthma despite mediumto-high doses of ICS therapy, blood eosinophils $\geq 400$ cells per $\mu \mathrm{L}$ and one or more exacerbations in the previous year. Patients in the control group who received reslizumab had a significant reduction in the frequency of asthma exacerbations (study 1 : rate ratio $0.50,95 \% \mathrm{Cl} 0.37-0.67$; study $2: 0.41$ (95\% Cl 0.28-0.59; both $\mathrm{p}<0.0001)$ compared with those receiving placebo.

\section{Conclusion}

Phenotyping asthma led to new therapeutic options and a personalised treatment approach. Pathogenesis of asthma, inflammatory pathways, severity of the disease and phenotypes are factors taken into consideration in order to choose proper therapy. Despite novel therapies' efficacy, they should be considered only in cases of uncontrolled severe asthma and only when other common causes of uncontrolled asthma, such as poor inhaler technique, poor adherence, comorbidities and modifiable risk factors, have been identified and minimised.

\section{Conflict of interest}

None declared.

This article has been corrected and republished to amend an error in the name of one of the authors.

\section{References}

1. Global Initiative for Asthma. Global Strategy for Asthma Management and Prevention. Updated 2017. http:// ginasthma.org/download/317/

2. Asher I, Pearce N. Global burden of asthma among children. Int J Tuberc Lung Dis 2014; 18: 1269-1278.

3. Chung KF, Wenzel SE, Brozek JL, et al. International ERS/ATS guidelines on definition, evaluation and treatment of severe asthma. Eur RespirJ 2014; 43: 343-373.
4. Lang A, Carlsen $\mathrm{KH}$, Haaland $\mathrm{G}$, et al. Severe asthma in childhood: assessed in 10 year olds in a birth cohort study. Allergy 2008; 63: 1054-1060.

5. Guilleminault L, Ouksel H, Belleguic C, et al. Personalised medicine in asthma: from curative to preventive medicine. Eur Respir Rev 2017; 26: 143.

6. Presta LG, Lahr SJ, Shields RL, et al. Humanization of an antibody directed against IgE. J Immunol 1993; 151: 2623-2632. 
7. Chang TW, Wu PC, Hsu CL, et al. Anti-IgE antibodies for the treatment of IgE-mediated allergic diseases. Adv Immuno 2007; 93: 63-119.

8. Normansell R, Walker S, Milan SJ, et al. Omalizumab for asthma in adults and children. Cochrane Database Syst Rev 2014; 1 : CD003559.

9. Sanderson CJ. Interleukin-5, eosinophils, and disease. Blood 1992; 79: 3101-3109.

10. Garcia G, Taille C, Laveneziana P, et al. Anti-interleukin-5 therapy in severe asthma. Eur Respir Rev 2013; 22: 251-257.

11. Deschildre A, Marguet C, Salleron J, et al. Add-on omalizumab in children with severe allergic asthma: a 1-year real life survey. Eur RespirJ 2013; 42: 1224-1233.

12. Beeh KM, Ksoll M, Buh R. Elevation of total serum immunoglobulin $E$ is associated with asthma in nonallergic individuals. Eur Respir J 2000; 16: 609-614

13. Pillai P, Chan YC, Wu SY, et al. Omalizumab reduces bronchial mucosal IgE and improves lung function in nonatopic asthma. Eur RespirJ 2016; 48: 1593-1601.

14. Magnan A, Bourdin A, Prazma CM, et al. Treatment response with mepolizumab in severe eosinophilic asthma patients with previous omalizumab treatment. Allergy 2016 71: 1335-1344

15. Abraham I, Alhossan A, Lee CS, et al. 'Real-life' effectiveness studies of omalizumab in adult patients with severe allergic asthma: systematic review. Allergy 2016; 71: 593-610.

16. Busse WW, Morgan WJ, Gergen PJ, et al. Randomized trial of omalizumab (anti-lgE) for asthma in inner-city children. NEnglJ Med 2011; 364: 1005-1015.

17. Humbert M, Beasley R, Ayres J, et al. Benefits of omalizumab as add-on therapy in patients with severe persistent asthma who are inadequately controlled despite best available therapy (GINA 2002 step 4 treatment): INNOVATE. Allergy 2005; 60: 309-316.

18. Tzortzaki EG, Georgiou A, Kampas D, et al. Long-term omalizumab treatment in severe allergic asthma: the SouthEastern Mediterranean "real-life" experience. Pulm Pharmacol Ther 2012; 25: 77-82.

19. Samitas K, Delimpoura V, Zervas E, et al. Anti-IgE treatment, airway inflammation and remodelling in severe allergic asthma: current knowledge and future perspectives. Eur Respir Rev 2015; 24: 594-601.

20. Djukanovic R, Wilson SJ, Kraft $M$, et al. Effects of treatment with anti-immunoglobulin $\mathrm{E}$ antibody omalizumab on airway inflammation in allergic asthma. Am J Respir Crit Care Med 2004; 170: 583-593.

21. Zietkowski Z, Skiepko R, Tomasiak-Lozowska MM, et al. Anti-IgE therapy with omalizumab decreases endothelin-1 in exhaled breath condensate of patients with severe persistent allergic asthma. Respiration 2010; 80: 534-542.

22. Kang JY, Kim JW, Kim JS, et al. Inhibitory effects of antiimmunoglobulin $E$ antibodies on airway remodeling in a murine model of chronic asthma. J Asthma 2010; 47: 374-380.

23. Roth $M$, Zhong J, Zumkeller C, et al. The role of IgE-receptors in IgE-dependent airway smooth muscle cell remodelling. PLoS One 2013; 8: e56015.

24. Riccio AM, Dal Negro RW, Micheletto C, et al. Omalizumab modulates bronchial reticular basement membrane thickness and eosinophil infiltration in severe persistent allergic asthma patients. Int J Immunopathol Pharmacol 2012; 25: 475-484.

25. Molimard M, Mala L, Bourdeix I, et al. Observational study in severe asthmatic patients after discontinuation of omalizumab for good asthma control. Respir Med 2014; 108 : 571-576.

26. Hanania NA, Wenzel S, Rosen K, et al. Exploring the effects of omalizumab in allergic asthma: an analysis of biomarkers in the EXTRA study. Am J Respir Crit Care Med 2013; 187: 804-811.

27. Bel EH, Wenzel SE, Thompson PJ, et al. Ora glucocorticoid-sparing effect of mepolizumab in eosinophilic asthma. N Engl J Med 2014; 371: 1189-1197.

28. Pavord ID, Korn S, Howarth $\mathrm{P}$, et al. Mepolizumab for severe eosinophilic asthma (DREAM): a multicentre, double-blind, placebo-controlled trial. Lancet 2012; 380 : 651-659.

29. Ortega HG, Liu MC, Pavord ID, et al. Mepolizumab treatment in patients with severe eosinophilic asthma. N Engl Med 2014; 371: 1198-1207.

30. Castro M, Zangrilli J, Wechsler ME, et al. Reslizumab for inadequately controlled asthma with elevated blood eosinophil counts: results from two multicentre, parallel, double-blind, randomised, placebo-controlled, phase 3 trials. Lancet Respir Med 2015; 3: 355-366

31. Li J, Wang F, Lin C, et al. The efficacy and safety of reslizumab for inadequately controlled asthma with elevated blood eosinophil counts: A systematic review and metaanalysis. J Asthma 2017; 54: 300-307. 